\title{
HUMAN EXPERIMENTATION: ETHICS IN THE CONSENT SITUATION
}

\author{
JoHN FLETCHER*
}

I

\section{Background for an Ethical Appraisal of the Consent Situation}

The coupling of the art of healing with the method of scientific investigation for medical research in human beings causes many profound questions to leap into the minds of those whose consciences have been shaped within democratic and religious institutions. Many medical investigators who have carried out research in human subjects have attempted to describe the professional-ethical conditions under which these questions must be resolved. ${ }^{1}$ A survey of the medical-legal literature and popularly written commentaries on experimental medicine likewise reveals a large number of essays attempting to supply the legal, political, medical, and moral dimensions of the several ways in which humans are presently utilized for research. ${ }^{2}$ The overriding legal and moral importance of the subject's informed con-

- B.A. 1953, University of the South; B.D. 1956, Virginia Theological Seminary; Fulbright Scholar, University of Heidelberg, 1956-57. Assistant Professor of Church and Society, Virginia Theological Seminary. Th.D. Candidate, Union Theological Seminary. Contributor to theological publications.

I wish to express my thanks to Roger L. Shinn and Charles Gozonsky for a critical reading of the first draft of this essay and for several helpful suggestions. Dr. Robert Farrier and the Reverend LeRoy Kerney of the Clinical Center, National Institutes of Health, Bethesda, Maryland, made it possible for the author to work in the ideal setting for study of the question of human experimentation. The essay does not necessarily represent the views of the National Institutes of Health.

${ }^{1}$ For the most extensive anthology and bibliography on the subject of human experimentation, see generally I. Ladimer \& R. Newiman, Clinical Investigation in Medicine (1963). The beginning inquirer will perhaps be aided in following the writing of Dr. Henry K. Beecher, a scientist who has earned the right to speak authoritatively on human experimentation. Beecher's writings prior to 1963 are cited in id. at 496. Later writings are Consent in Clinical Experimentation: Myth and Reality, 195 J.A.M.A. 34 (1966); Some Guiding Principles for Clinical Investigation, 195 J.A.M.A. I135 (1966); Ethics and Clinical Research, 274 NEw ENG. J. MED. 1354 (1966).

${ }^{2}$ Some 500 articles and books are collated in I. LADIMER \& R. NewMan, supra note I, at 494-516. Since 1963 some of the most informative writings are the following: Ethics IN Medical Prockess (G. Wolstenholme \& M. O'Connor eds. I966) [hereinafter cited as Ethics IN Mrdical Progriss] (with special reference to transplantation); Natronal Academy of Sciences, National Researchi Councir, UsB of Human Subjects in Safety Evaluntion of Food Chemicals (Proceedings of a Conference, 1967); Alexander, Limitations of Experimentation on Human Beings with Special Reference to Psychiatric Patients, 27 Disenses NeRv. SYst. 61 (Monograph, July 1966); Freund, Ethical Problems in Human Experimentation, 273 NEW ENG. J. MED. 687 (1965); Langer, Human Experimentation: Cancer Studies at Sloan-Kettering Stir Public Debate on Medical Ethics, I43 ScI. 551 (I964); Langer, Human Experimentation: New York Verdict Affirms Patients' Rights, 151 Scr. 663 (1966); Morse, Legal Inplications of Clinical Investigations, 20 VAND. L. REv. 747 (1967); Ruebhausen \& Brim, Privacy and Bchavioral Research, 21 Aм. Psychologist 423 (1966); Scribner, Ethical Problems of Using Artificial Organs 20 Sustain Life, io Transactrons Axs. Soc'y Artificial Internal Organs 209 (1964); Stumpf, Some Moral Dimensions of Medicine, 64 Annals InTernar Med. 460 (1966); Wolfensberger, Ethical Issues in Research with Human Subjects, 155 Scr. 47 (1967); Comment, Experimentation on Human Beings, 20 Stan. L. Rev. 99 (1967); Editorial, Moral Problems in the Use of Borrowved Organs, Artificial and Transplanted, 60 ANNAIs INTERNAI Med. 309 (1964); Editorial, The Experimental Use of Human Beings, 65 ANNAIS INTERNAL Med. 37x ( 1966$)$. 
sent to the experiment is widely noted, but nowhere in the broad and varied literature is there an empirically based study of the interactions of those who give and those who obtain this consent. The consent situation has been treated heavily from the vantage point of principle but lightly from the ground of practice.

This article attempts to assess the potential in the existing legal and professionalethical environment for continuing legal and moral conflict over the validity of a subject's consent to experimentation. The approach adopted, however, is that of a student of ethics, and the study proceeds to explore the conditions of consent-giving in this light and to formulate, from this same ethical perspective, some untested but promising hypotheses for the improvement of the consent situation itself. The reader may be interested to see how the law and professional ethics of human experimentation, and current practices, coincide with or diverge from the conclusions ventured here.

\section{A. The Legal and Professional-Ethical Context}

Since the formulation of the Nuremberg Code in $1947,{ }^{3}$ there have been a number of other codifications by international and national professional medical bodies. ${ }^{4}$ These formulations essentially embody the ten well-known criteria of the Nuremberg Code. In addition, and of special legal interest, there are several important regulations, directives, and policy memoranda spelling out procedures within research institutions themselves.

In this country the most influential of these quasi-legal mandates originate within the federal government and its health agencies. In July 1966 , the Surgeon General issued a policy and procedure statement to all grantee institutions, ${ }^{5}$ in which requirements for review to insure the rights of individuals involved in clinical research were set forth. In substance the directive stipulated that no grants in support of research were to be continued or awarded unless arrangements were made for consideration of proposals for research involving human subjects by the author's institutional associates in a committee organized along interdisciplinary lines. In brief, these institutional committees are charged with determining three things: (I) that the rights and welfare of those involved are protected, (2) that appropriate methods

${ }^{3}$ Trials of War Criminals Before Nuremberg Military Tribunals Under Control Council Law No. Io, 2 The Medical Case I8I (1947), reprinted in Beecher, Experimentation in Man, 169 J.A.M.A. 46r, 47274 (1959).

American Psychological Association, Ethical Standards of Psychologists, 44 AM. PsychoLogist 279 (1959); World Medical Association, Code of Ethics of the World Medical Association [Declaration of Helsinki], 2 BRrr. MED. J. 177 ( 1964 ) (accepted at Helsinki in June I964); Medical Research Council, Responsibility in Investigations on Human Subjects, 2 BrIT. MED. J. I78 (r964) (statement in Annual Report for $1962-63$ ); American Medical Association, Ethical Guidelines for Clinical Investigation (approved by House of Delegates on Nov. 30, 1966), in Declaration of Helsinki and AMA Ethical Guidelines for Clinical Investigation (undated pamphlet printed by the AMA).

'Surgeon General, Public Health Service, Dep't of Health, Education, and Welfare, Investigations Involving Human Subjects, Including Clinical Research: Requirements for Review to Insure the Rights and Welfare of Individuals, PPO r29, Revised Policy July I, I966. 
are used to obtain informed consent, and (3) that the risks of the procedure are proportionate to the potential medical benefits. ${ }^{6}$

A memorandum was issued on the same date from the Office of the Director of the National Institutes of Health (NIH) outlining the group consideration and informed consent practices which would obtain for each Institute. ${ }^{7}$ An ascending system of review committees, beginning in each Institute, rising to a Clinical Research Committee of the Medical Board, and culminating in the Medical Board itself, was arranged to pass on ( $I$ ) all research projects involving the participation of normal volunteers, (2) therapeutic or diagnostic studies with unusual hazard which might be referred for approval, and (3) nondiagnostic, nontherapeutic studies involving patients which might be referred. Expectations of voluntary and informed consent of patients and volunteers were outlined along with procedures for making records of such information. In the realm of principles, the statement underlined these as central to clinical research: (I) group consideration, (2) informed consent of the patient or volunteer, and (3) the freedom of the subjects to withdraw from a project at any time. As many research institutions model their practices after NIH, the effects of this memorandum, coupled with the significant changes brought about by the policy statements of the Surgeon General, extend far beyond their source. The Institutes, with a proposed budget for Ig68 of \$T.4 billion, now support some 65,000 senior researchers, over 2,000 research and training institutions, and 30,000 clinical and basic scientists who are undergoing additional training. ${ }^{8}$

In carrying out the requirements of the federal Food, Drug and Cosmetic Act ${ }^{0}$ in the freld of regulating the use of investigational drugs in interstate commerce, the Food and Drug Administration has recently required the written consent of the patient in all cases where investigational drugs are administered. ${ }^{10}$ The regulation itself develops criteria to judge meaningful consent and furnishes examples of situations when exceptions to the written consent requirement may be made by the physician. In these latter respects the regulation is unprecedented, and the document could prove to be a significant collateral source of standards governing consent. The specific exceptions to the general rule of written consent will be discussed later in this paper.

Occasional statutes and formal codes of professional ethics may furnish other

\footnotetext{
${ }^{\circ} I d$.

${ }^{7}$ Memorandum on Group Consideration and Informed Consent in Clinical Research at the National Institutes of Health, from Director, National Institutes of Health to Institute Directors et al., July $\mathrm{r}$, 1966.

${ }^{8}$ Medical World News, July $7, \mathrm{x} 967$, at $6 \mathrm{7}$, col. 3 .

${ }^{5} 2$ Stat. 1040 (1938), as amended, 21 U.S.C. $\$ \$ 301-392$ (1964, Supp. II, 1965-66).

${ }^{10}$ Food and Drug Reg. $\$ 130.37,32$ Fed. Reg. 8753 (rev. June 20, 1967). For legal discussion the reader should note Morse, supra note 2, at 762,763 . For interpretation of FDA policy and history of the amendment, see Gottlieb, Federal Legislation and Regulations, in Natronal Academy or Sciences, supra note 2 , at $175-8 \mathrm{r}$.
} 
sources of standards for clinical investigation. ${ }^{11}$ A further source, in the form of precedent which, while not binding, is persuasive in establishing professional practice, might be directives stating expectations or memoranda describing actual practices in outstanding institutions. Another source might be judicial precedent, but the legal situation with regard to judicial decisions on the appellate level concerned with human experimentation has not changed since Sessoms noted as follows in 1958 :

No reported court decision has considered research specifically in terms of the right and liability of a trained professional to use a living patient or a normal subject as a means of discovering new knowledge not necessarily of direct benefit to that patient or subject. None of the cases that have actually come before the appellate courts have involved a real scientist observing the proper precautions and giving primary consideration to the welfare of his patient. ${ }^{12}$

There is, however, one important decision by an official, quasi-public American body in regard to a specific case. This was the censure in 1966 by the Regents of the University of the State of New York of Drs. Southam and Mandel..$^{13}$ The Regents have jurisdiction in New York over all public and private education and all licensed professions except the practice of law. It is composed of fifteen members elected for fifteen-year terms by both houses of the New York legislature. After their examination of the charges that the two physicians had not obtained adequately

\footnotetext{
${ }^{11}$ Ladimer, Ethical and Legal Aspects of Medical Research on Human Beings, in I. LADIMER \& R. NeWMan, supra note $\mathrm{I}$, at 195.

${ }^{13}$ Sessoms, Guiding Principles in Medical Research Involving Humans, Hosp., Jan. I, I958, at 44, 60.

${ }^{13}$ For discussion of the decision of the Board of Regents of the State of New York, see Carley, Patient Consent to Research: Rules Set, Wall Street Journal, Jan. 2r, 1966, at 12, col. 4; Lear, Experiments on People-The Growing Debate, SAT. Rev., July 2, 1966, at 4I; Langer, Human Experimentation: New York Verdict Affirms Patients' Rights, ${ }_{51} 1$ ScI. 663, 664, 665 (1966). The Medical Grievance Committee of the Board of Regents of the State of New York initiated an investigation of the experiments following legal action by a member of the board of directors of the Jewish Hospital for Chronic Diseases, William A. Hyman, to inspect charts, records, death certificates, laboratory data, and so forth, pertaining to the patients participating in the experiments. Hyman v. Jewish Chronic Disease Hosp., 42 Misc. $2 \mathrm{~d}$ 427, 248 N.Y.S.2d 245 (Sup. Ct. 1964), rev'd per cturiam, 2I App. Div.2d 495, 25ז N.Y.S.2d 8I8, rev'd, I5 N.Y.2d 3I7, 206 N.E.2d 338, 258 N.Y.S.2d 397 (1965). Hyman's motion was granted by the Supreme Court. On appeal by the hospital the Appellate Division of the Supreme Court reversed the previous decision on the basis of law and facts, but on grounds unrelated to standards for clinical investigation. This decision was appealed by Hyman, and the Court of Appeals reversed the second decision, holding that the director was entitled to an inspection of such records to investigate alleged improper experimentation on patients. The issue of confidentiality was to be solved by inserting an order that names of particular patients be kept confidential as the director inspected the records. Although the Hyman case was conducted on grounds of the rights of a member of a hospital board to inspect records when improper activities of the hospital were in question, the Appellate Division of the Supreme Court of New York did make the following observation as to standards for consent:

"The Hospital's future policy will be in accordance with petitioner's contention that experiments such as the one here involved should be done only with the patient's written consent after the patient has been properly informed. On' September 7,1963 , the Hospital's Grievance Committee approved the experiment. On September 30,1963 , its board of directors approved its Grievance Committee's report. On January 27,1964 , the Hospital's Research Committee approved continuance of the cancer immunization studies, but only upon the written, informed consents of the patients."

21 App. Div. 2d at 499, 25 I N.Y.S.2d at 822.
} 
informed consent for the injection, in the course of an experiment, of cancer cells into twenty-two hospitalized and seriously ill patients, the Regents found the two guilty of obtaining consent fraudulently. The object of the procedure-to test the immune response in seriously ill persons-was not in question, but the method of obtaining consent was. Even though the cells were felt to be harmless to the patients, it was judged that because the investigators had not specifically stated what kind of cells were being injected, material information necessary to make an informed decision was withheld. The Regents suspended the licenses of the doctors for one year and then stayed this decision on condition of good behavior.

This decision is of legal significance because it was made by a legislatively appointed body and could possibly be persuasive to a court deciding a case involving similar circumstances. Of perhaps deeper significance is the vast effect that this widely publicized decision had in deepening public awareness of medical research in humans and of the central importance of informed consent. ${ }^{14}$

\section{B. The Ascendency of Research}

There are many indicators showing the increasingly rapid growth of medical research, as well as of research in the social sciences. Figures available through NIH show the following rise in appropriations for on-site and off-site research: $:^{15}$

$\begin{array}{ccc} & \text { Off-site } & \text { On-site } \\ 1965 & \$ 545,000,000 & \$ 77,000,000 \\ 1966 & 604,000,000 & 82,700,000 \\ \text { I967 } & 681,000,000 & 90,000,000\end{array}$

As an indicator of the financial commitment to research and its expansion through use of federal funds, the breakdown of figures in Table I confirms the general growth of research in all of the sciences. These figures indicate that behind such expenditures is a value commitment to a scientific foundation for the pursuit of sounder health and treatment of disease. The expanding system of research, however, multiplies the incidence of the utilization of human beings in its process, for there comes a point in the continuum of the experimental process when testing must be done in human subjects in order to complete the information necessary to application of new drugs or therapies. Moreover, the very magnitude of the funds available is a source of temptation to those who might find reasons to attach more importance and prestige to such funds than to the quality or necessity of research done. It is also sobering to reflect on the fact that this vast research "industry" cannot be maintained without human research subjects.

\footnotetext{
14 See generally Lear, supra note 13; Goodman, Doctors Must Experiment on Humans, But What are the Patient's Rights?, N.Y. Times, July 2, $1967, \$ 6$, at 12, col. 1 .

${ }^{15}$ Figures available through the office of Dr. John Sherman, National Institutes of Health. These figures include appropriation for the National Institute of Mental Fealth which became a separate bureau in 1966 . The figures for 1967 include appropriations to the Division of Environmental Health.
} 
TABLE I

(millions of dollars)

Summary of Federal Funds for Research,

Fiscal Years 1965 , Ig66, x967

Field of Science

Physical sciences, total

Life sciences, total

Medical sciences

Biological sciences

Social sciences

Psychological sciences

Agricultural sciences

Source: National Science Foundation ${ }^{16}$

\section{5}

(actual)

$3,370.3$

I, $\mathbf{1 8 2 . 9}$

819.4

258.I

127.4

103.5

Total $\frac{105 \cdot 3}{5,863 \cdot 4}$
1966

(estimated)

$3,680.7$

I, 352.4

953.I

283.9

I 88.4

136.7

$\frac{\mathrm{II} 5 \cdot 4}{6,7 \pm 0.6}$
1967
(estimated)

$3,649.2$

$\mathrm{I}, 427.4$

$\mathrm{r}, 015.9$

302.9

221.9

157.9

$\frac{108.7}{6,883.9}$

\section{Values and Decision Making in Research}

It may be observed that within the process of research activities there are several different occasions for decision making in which the socio-moral values of the decision-makers become more visible. Moving from the collective to the individual levels, at least three settings for decision making may be located.

\section{Social Policy Decisions}

Basic policy decisions as to which physical, social, or environmental conditions deserve attention, funding, and personnel are made against the background of a certain policy structure. The goals envisioned by policy makers have a crucial effect on how human beings will be involved in research. ${ }^{\mathbf{1 7}}$ Ethical questions can be fruitfully raised at this level, both as to the realism of goals and the ways in which policy makers intend and visualize the world. Imbedded in their decisions are images, drawn from many sources, which have a theological dimension insofar as commitment and loyalties are involved. Unfortunately, treatment of policy making at this level is beyond the scope of this paper.

\section{Institutional Decision Making}

Turning to the question of assessment of the scientific value and quality of design of each proposed experimental project, it would appear that effective schemes of interdisciplinary group consideration are a useful means of critique. However, a thorough study of the group consideration process in several research settings

\footnotetext{
${ }^{10}$ National Science Foundation, NSF 66-25, Federal Funds for Research, Development, and Other Scientific Actrvities 77, 78 (I966).

${ }^{17}$ See generally Weinberg, Criteria for Scientific Choice, I Minerva I59, I7I (I963); R. Dubos, Man Adapting 455 (1965); Simpson, Biology and the Public Good, 55 AM. Sc1. I6r (I967); Gorovitz, Ethics and the Allocation of Medical Resources, 5 Med. Resenrch Enginenring 5, 7 (I966).
} 
remains to be done and would be an important addition to the literature on the sacial setting of human experimentation. The author's consultation with a number of investigators and officials ${ }^{18}$ indicates that group consideration can be a reliable and just method of preventing the "thoughtless and careless" experiments which Beecher has criticized. ${ }^{19}$

The group consideration process is not infallible, for any process managed by human beings is subject to domination by the self-interest of an individual or clique. Enthusiasm for a particular project by a popular member or a desire for speed in decision could subdue challenges from other members. It is notable, however, that no legal challenges have arisen at this level of decision making. All of the rules of the Nuremberg Code can be effectively implemented through this method of regulation, depending upon the objectivity and freedom of members of the group to challenge proposals. The group review process would appear to be effective in estimating the significance of the experiment, its necessity, the calculated risks in proportion to the importance of the benefits, the conditions and protocol for the experiment, and the skills and training of the investigators. Rules regarding termination of the experiment by subject or investigator, and the rule regarding consent, are less amenable to implementation through group review since they presuppose a transaction between those persons, though in regard to each of these rules the advisory group may review methods of obtaining consent and effecting termination.

\section{Investigator Subject Decision Making}

Experiments in medical research may be designed to study a general condition which the patient presents, but the conduct of the study may not aid the patient directly. This kind of study is for the purpose of enlarging the general knowledge of medicine and is referred to in this paper as "nonbeneficial." Other studies may be designed to test diagnostic or therapeutic procedures and thus may have a direct "beneficial" effect upon the patient. Experimental subjects for all studies may include patients as well as normal volunteers. The complexity of the issues that arise stems from the great variety in the types of research, the varying degrees of risk and potential benefit, and the variations possible in the prospective subject's personality and physical condition; when the categories of minors or persons too ill to give consent are added, new participants in the form of guardians, parents, or other representatives of the patient may appear, adding additional permutations to existing complexity.

Article I of the Nuremberg Code charges the principal scientific investigator with the responsibility of obtaining informed consent and with being the judge of

\footnotetext{
${ }^{18}$ Twenty interviews were conducted by the author, June-Aug. 1967 , in the Clinical Center, National Institutes of Health, with senior investigators, administrators, and legal advisers.

${ }^{20}$ Beecher, Ethics and Clinical Research, 274 NEw ENG. J. MED. 1354, 1356-59 (1966).
} 
the quality of that consent. Each of the possible combinations of investigator-subject relations deserves careful study from the legal and ethical points of view. Only the outlines of such studies can be suggested in this paper.

\section{Interests Involved in the Consent Situation}

\section{A. Indications of the Critical Importance of Consent}

Within the complex of problems associated with human experimentation, there are several reasons to conclude that the consent situation will be the focal point of the most serious legal difficulties and moral dilemmas.

First, in twenty interviews conducted by the author in the summer of Ig67 among physicians, investigators, and legal officers in NIH's Medical Center, the most commonly mentioned "difficulty" in human experimentation was the problem of informed consent. Specifically, in fifteen of the twenty interviews informed consent for nontherapeutic procedures in ill persons was said to be the most intensely felt moral problem. Such perceptions by persons actively involved in experimentation with humans are both indicative of the importance of consent and reassuring as to the attitudes prevalent among researchers.

Second, the consent situation has come to represent the primary encounter of legal significance between investigator and subject. In discussing tort liability in relation to medical research, Ladimer notes, "the essence of tort liability, other than that arising out of some form of negligence-for which the general rules established in malpractice cases are applicable-would in large measure depend on the scope and validity of the consent obtained."20 Pointing out the contractual aspect of the legal relation between investigator and subject, he concludes that

The essence of the research contract lies in the complete understanding of the parties.

Assuming there is complete understanding and no unequal bargaining, a research contract involving scientifically and morally acceptable research can stand against trespass and liability for unauthorized invasion. ${ }^{21}$

Third, in the research continuum the consent situation may occur as one of the last steps in preparation for the initiation of the experiment. The significance of the consent situation is, for this reason, open to being overshadowed by the expense, effort, and technicalities in which the investigator has been involved prior to this time. Subjects and patients may hear of the experiment, its risks, and its conditions only once. On the other hand, much preparation on the part of the investigators has preceded encounters for consent purposes. There is thus a built-in

\footnotetext{
${ }^{20}$ Ladimer, supra note II, at 200.

${ }^{22}$ Id. at 207.
} 
element of "incommensurate preparation" on the part of participants which is unavoidable in the experimental environment. This factor may influence the mode of interaction in the consent situation and calls for its special scrutiny.

Fourth, the outstanding public challenges to medical ethics in human experimentation have centered ultimately on the consent situation. The MandelSoutham case is the leading American instance, while the two cases of greatest interest abroad have concerned consent questions in combination with the problem of the proper definition of death. ${ }^{22}$ The public seems conditioned to human experimentation and to have recognized the central importance of consent in determining its legal and ethical propriety.

Fifth, a survey of the language of the formulated rules governing human experimentation, including their qualifications and exceptions, reveals that apprehensions of possible conflicts of interest in the consent situation manifest themselves repeatedly. The following section catalogues the published rules and documents the manner in which consent has become in Western society the key to the legitimacy of scientific experimentation on human subjects.

\section{B. Legal and Ethical Formulations and the Issues They Raise}

The law and professional ethics of consent to human experimentation reflect, in part at least, the concern of society that conflict of interest may disable a scientific investigator from exercising the independent, disinterested, and conscientious judgment that alone might legitimize employing a human subject for research purposes without his knowledge or against his will. Whether a broader ethical principle arising from theological concern is also at work is a question we reserve for treatment subsequently.

Conflicts of interest in human experimentation may originate either in the investigator's anticipation of the social benefits which are expected to result from the study or in the investigator's personal investment of his skill, prestige, and selfimage. In either case, there results a conflict with the professional's responsibility for the welfare and protection of the subject, a responsibility that is only the more obvious where the subject for some reason lacks full control over his own capacity to give or withhold consent. The law and medical ethics wisely do not inquire as to the source of the conflict with the possible object of distinguishing the disinterested investigator from the man who might allow his personal involvement to

\footnotetext{
${ }^{22}$ The legal questions in Hyman $\nu$. Jewish Hospital for Chronic Diseases and the Regents' decision are discussed in note 13 supra. Two European cases of interest involve transplantation of a kidney from a person with severe brain damage to critically ill renal patients. In each case the donor was, in the view of the physicians, irreparably damaged; one died two days later, the second was found to be "legally" dead after the nephrectomy when the respirator was disconnected. Although the closest relative had given consent to the donation, in each case the physician was charged with manslaughter in contributing to the "death" of the donor. I4 Clev.-Mar. L. Rev. 467 (1963); 3I Meb. Legal J. 195 (1963); see Louisell, Transplantation: Existing Legal Constraints, in ETHics in Medical Progress 92-93.
} 
affect his judgment; the conflict is held to exist in every case, and the subject's free and informed consent is made an almost unvarying requirement.

The exceptions to the requirement that the individual subject's consent be obtained fall largely into three classes: (I) If the subject is legally unable to give consent due to mental incapacity or minority, his legal representative's consent may be held acceptable; (2) if complete disclosure might be harmful to the subject's mental or physical health, the physician may be allowed to dispense with a full explanation of risks; and (3) where the experiment depends in some material way on the subject's ignorance, consent may not be insisted upon. Exceptions of the class (I) variety were omitted from the Nuremberg Code but have been standard in subsequent formulations. The following extensive excerpts from some of the important formulations reveal various qualifications of the requirement of informed consent and furnish evidence of the continuing potentiality for conflicts of interest in the research situation:

\section{World Medical Association, Code of Ethics \\ (Declaration of Helsinki) ${ }^{23}$}

\section{Clinical Research Combined with Professsional Care} ....

If at all possible, consistent with patient psychology, the doctor should obtain the patient's freely given consent after the patient has been given a full explanation. In case of legal incapacity consent should also be procured from the legal guardian; in case of physical incapacity the permission of the legal guardian replaces that of the patient.

Non-therapeutic Clinical Research ....

3a. Clinical research on a human being cannot be undertaken without his free consent, after he has been fully informed; if he is legally incompetent the consent of the legal guardian should be procured.

$3 \mathrm{~b}$. The subject of clinical research should be in such a mental, physical, and legal state as to be able to exercise fully his power of choice.

\section{Medical Research Council (Great Britain), Responsibility in Investigations on Human Subjects ${ }^{24}$}

Control Subjects in Investigations of Treatment or Prevention Such controlled trials may raise ethical points which may be of some difficulty. In general, the patients participating in them should be told frankly that two different procedures are being assessed and their co-operation invited. Occasionally, however, to do so is contraindicated. For example, to awaken patients with a possibly fatal illness to the existence of such doubts about effective treatment may not always be in their best interest; or suspicion may have arisen from suggestion, and it may be necessary to introduce a placebo into part of the trial to determine this. Because of these and similar difficulties it

\footnotetext{
${ }^{23}$ World Medical Association, supra note 4.

${ }^{24}$ Medical Research Council, supra note 4.
} 
is the firm opinion of the Council that controlled clinical trials should always be planned and supervised by a group of investigators and never by an individual alone.

\section{Federal Food, Drug and Cosmetic Act}

[E]xperts using such drugs for investigational purposes certify to such manufacturer or sponsor that they will inform any human beings to whom such drugs, or any controls used in connection therewith, are being administered, or their representatives, that such drugs are being used for investigational purposes and will obtain the consent of such human beings or their representatives, except where they deem it not feasible or, in their professional judgment, contrary to the best interests of such human beings.

\section{Food and Drug Administration Regulation ${ }^{26}$}

This means that the consent of such humans (or the consent of their representatives) to whom investigational drugs are administered primarily for the accumulation of scientific knowledge, for such purposes as studying drug behavior, body processes, or the course of a disease, must be obtained in all cases and, in all but exceptional cases, the consent of patients under treatment with investigational drugs or the consent of their representatives must be obtained.

When consent is necessary under the rules set forth in this section, the consent of persons receiving an investigational new drug in Phase $I$ and Phase 2 investigations (or their representatives) shall be in writing. When consent is necessary under such rules in Phase 3 investigations, it is the responsibility of investigators, taking into consideration the physical and mental state of the patient, to decide when it is necessary or preferable to obtain consent in other than written form. When such written consent is not obtained, the investigator must obtain oral consent and record that fact in the medical record of the person receiving the drug.

\section{Board of Regents of State of New York, Decision in the Southam-Mandel Case ${ }^{27}$}

No consent is valid unless it is made by a person with legal and mental capacity to make it, and is based on a disclosure of all material facts. Any fact which might influence the giving or withholding of consent is material .... We do not say that it is necessary in all cases of human experimentation to obtain consents from relatives or to obtain written consents.

\section{American Medical Association, Ethical Guidelines for Clinical Investigation ${ }^{28}$}

3. In clinical investigation primarily for treatment-

In exceptional circumstances and to the extent that disclosure of information concerning the nature of the drug or experimental procedure or risks would

${ }^{25} 21$ U.S.C. $\$ 355 i$ ( 1964$)$.

${ }^{28} 32$ Fed. Reg. 8753 (I967).

${ }^{27}$ Reprinted in Langer, supra note 13 , at 664-65.

${ }^{28}$ American Medical Association, supra note 4 . 
be expected to materially affect the health of the patient and would be detrimental to his best interests, such information may be withheld from the patient. In such circumstances such information shall be disclosed to a responsible relative or friend of the patient where possible.

4. In clinical investigation primarily for the accumulation of scientific knowledge....

C. Minors or mentally incompetent persons may be used as subjects only if:

i. The nature of the investigation is such that mentally competent adults would not be suitable subjects.

ii. Consent, in writing, is given by a legally authorized representative of the subject under circumstances in which an informed and prudent adult would reasonably be expected to volunteer himself or his child as a subject.

D. No person may be used as a subject against his will.

\section{US. Public Health Service, Clinical Investigations Using Human Beings as Subjects ${ }^{29}$}

No subject may participate in an investigative procedure unless:

(a) $\mathrm{He}$ is mentally competent and has sufficient mental and communicative capacity to understand his choice to participate; and

(b) $\mathrm{He}$ is $2 \mathrm{I}$ years of age or more, except that if the individual be less than 2I, he may participate in a procedure intended and designed to protect or improve his personal health or otherwise for his personal benefit or advantage if the informed written consent of his parents or legal guardian be obtained as well as the written consent of the subject himself if he be mature enough to appreciate the nature of the procedure and the risks involved.

The issues of law and interpretation raised by exceptions to the consent requirement formulated as above are discussed in connection with their ethical significance at a later point.

\section{III}

\section{Obtaining Consent for Medical Research: Ethical Reflection}

As indicated earlier, there is a spectrum of ethical issues associated with research in man; this spectrum includes (a) broad social policy goals, underlying which are fundamental images of man and society; (b) the scientific value, timing, and design of the experiment; $(c)$ the informed consent of the subject; and $(d)$ the conditions surrounding publication and application of the findings of the study to wider groups. Consent questions can be seen most clearly within the perspective of the "research continuum," and each consent situation must be judged within its own contextual setting and in terms of the specific participants.

Stumpf, a moral philosopher, in the context of grappling with the social and moral setting of human experimentation, has raised the question whether consent on the part of the patient is the decisive question in medical research. ${ }^{30}$ Although

\footnotetext{
${ }^{20}$ U.S. Public Health Service, Dep't of Fealth, Education, and Welfare, Clinical Investigations Using Human Beings as Subjects, Bureau of Medical Services Circular No. 38, June 23, 1966.

${ }^{30}$ Stumpf, supra note 2, at 468.
} 
he never answers his own query specifically, Stumpf does place a heavy emphasis, as others have, upon the significance of the "mood and basically internal control physicians possess when they engage in experiments."31 After pinpointing what, to him, is the most significant control in experimentation-the professional and ethical sensitivity of the physician-Stumpf proceeds to recognize a general communal acceptance of medical experimentation. He then shifts his emphasis to distilling from the values of this consensus a set of moral principles to "delineate some acceptable boundaries and limits to the use of human beings in research." 32 The third of four principles he delineates-the necessity to treat men as persons-is the source of Stumpf's comments on consent. He observes,

Indeed, the usual stress upon the element of consent in experiments is a recognition that the act of consent is what is entailed in being a person. A person can be used as a thing whenever his conscious capacity to respond to the truth is denied to him. Consent is not always feasible, nor is consent always decisive as we pointed out before. 33

Stumpf's sense of the importance of relating the goals of research to acceptable limits well meets the aim of the search of modern science for relation to the communal conscience while engaging in startling innovation. If a moralist did try to draw the line of ethical seriousness across the activities in medical research only at the question of consent, he would distort the actual situation and fail to address other important questions. If there is no single issue in medical research which can realistically be treated as the decisive issue (including the internal control of physicians), there is value in asking in what sense consent may be decisive within the complex of the several kinds of moral issues previously mentioned. On the basis of a study of the literature, interviewing in the field, and observation of a number of consent situations, ${ }^{34}$ it appears to this writer that the conduct of the consent situation is decisive for the patient's or volunteer's sense of being respected as a person, especially when the request is for a procedure which is nonbeneficial.

Obviously, the consent situation is decisive of the legal outcome. To the degree that the subject is furnished with facts and is capable of a response, he assumes risks of legal significance, or his representative assumes them for him. On this occasion the researcher also assumes legal responsibility for having complied with the existing rules and standards governing consent. The legal significance thus attached to this step results in its being given a degree of solemnity that might otherwise be lacking,

\footnotetext{
${ }^{31} I d$. at 469 .

$32 I d$. at 468 .

${ }^{33} I d$. at 469 .

as Five consent situations were observed by the author. The possible forms of consent were covered: ill person for therapeutic study, ill person for nontherapeutic study, parent of minor for consent to therapeutic study, normal volunteer for consent to nonbeneficial study. The one remaining possibility which was not observed was parent of minor or representative of an incapacitated patient for nontherapeutic study.
} 
and this in turn promotes on both sides the sense of the transaction's ethical importance.

The consent situation in medical research is formally constituted when a request for participation is initiated by a scientist to another individual or group (who may be either ill or normal); participation would involve some alteration of the subject's mental, physical, or social functioning, with the scientist planning to observe and record the results. The subject is asked to surrender, temporarily, some personal rights with a possibility of risk or discomfort. ${ }^{35}$

The consent situation has a formal moral dimension insofar as the subject or patient is a "person," with all the rights, status, and symbolic significance that term implies. He is a being whose humanity calls for the respect of the scientist, since in their common humanity they are equals, and no amount of rationalization can erase the resistance to one man's being used by another strictly as a means to an end. Experimentation of the nonbeneficial variety involves the use of a man as a means to improving the welfare of the human species, but societal values provide no sanction for the experimenter based on the desirability of the goal in view. The last credential evidencing the legitimacy of the experiment must, as a general rule, be conferred by the subject himself. This principle is embodied in the law and in professional practice and provides the foundation for ethical reflection on the methods of its application and on the exceptions to it deemed expedient for the general good.

What is new and what is permanent here? In one sense, the consent situation is a uniquely modern social interaction, dramatizing an aspect of the difficulty of reconciling the ethic of the scientific mission with our society's other values. Experimentation is as old as medicine, but the routinization-through professional and governmental influences - of the practice of obtaining consent to experimentation is uniquely modern. Such structural arrangements to meet the requirements of the communal conscience can both insure the freedom of men to experiment and protect those who participate. Men could not conduct medical experiments if they did not enjoy that creativity of spirit which springs from self-transcendence. Yet these same men cannot afford to pursue experimentation without legal and moral arrangements to protect the individual against accumulations of power. Selfinterest in its collective forms can destroy as effectively as self-transcendence can create. ${ }^{36}$

What is permanent in the consent situation is the encounter between selves when the limits of one self touch the limits of another. The underlying moral problem of the consent situation is the possibility of its depersonalization through excessive

\footnotetext{
${ }^{35}$ This definition is drawn from several places in medical literature where experienced investigators give definitions of the experimental process. Shimkin, The Problem of Experimentation on Human Beings: The Research Worker's Point of View, in I. LAdIMER \& R. NewMan, stupra note I, at 58; Ladimer, supra note $\mathrm{II}$, at $\mathrm{x} 90$; Wolfensberger, supra note 2, at 49.

${ }^{30}$ Guttentag, The Problem of Experimentation on Human Beings: The Physician's Point of View. II7 Sci. 207, 210 (r953); P. Trllich, The Protestant Era il5 (1960).
} 
secrecy and the arrogation of the right to know and to choose, which right belongs, in principle if not in fact, to each man. Tillich has located the basic structure of moral interaction:

Without this resistance of the "thou" to the "ego," without the unconditional demand embodied in every person to be acknowledged as a person in theory and practice, no personal life would be possible. A person becomes aware of his own character as a person only when he is confronted by another person. $0^{37}$

The discussion which now follows moves through three levels of examination: (a) the context of the consent situation; (b) constituted rules for consent; and (c) ethical principles. ${ }^{38}$

\section{A. The Context of the Consent Situation}

The intent of this part is to record, from the consent-giving settings in which interviews were held and observations were made, the ideas, sentiments, and attitudes of the parties to human experimentation. In particular, the consent-giving process is examined for forces interfering with the "free" exercise of the power to give or withhold consent.

Since the publication of the Nuremberg rule on consent, perhaps the main point of difference between those involved in public debate over its significance has been the stringency of the definition of informed consent. Reflecting on the strictness of language used to define consent, Welt comments:

There are, no doubt, a small number of subjects, perhaps the investigators themselves, who may be properly qualified to grant consent in terms of the quality of consent which is demanded here. However, in many instances it is certainly impossible either to evaluate the risks this precisely or to communicate with the subject in such a fashion that he freely sees the problem in all the dimensions that are necessary for proper consent. ${ }^{39}$

Other investigators echo this reaction to the rule and plead that informed consent is "a goal toward which to strive"40 or that there may be inherent limitations to what a patient can consent to. ${ }^{41}$

Investigators, in person and in their writings, participate in the public debate about consent with highly mixed sentiments. There is in no sense a uniform or standardized attitude prevalent in this field, but if there was a consensus on the

\footnotetext{
${ }^{37}$ P. TiLIICH, supra note 36 , at 125 .

${ }^{38}$ It would require too lengthy a footnote to account for the many sources utilized in the discussion of rules and principles which follows. The principal recent works which figure in the author's point of view here are H.D. Aiken, Reason and Conduct (1962); Josephi Fletcher, Situation Ethics (ig66); H.R. Niebuhr, The Responsible Self (ig63); J. Piaget, The Moral Judgment of the Child (1932); P. Tirlich, Systematic Theology III (1963); Gustafson, Context Versus Principles-A Misplaced Debate in Christian Ethics, 58 HaRv. Theol. Rev. $17 \mathrm{I}$ (1965).

${ }^{39}$ Welt, Reflections on the Problems of Human Experimentation, 25 CoNN. MED. 77 (1961).

${ }^{10}$ Beecher, Consent in Clinical Experimentation: Myth and Reality, I95 J.A.M.A. 34 (1966).

¿1 Beeson et al., Panel Discussion: Moral Issues in Clinical Research, 36 YALE J. B10. \& MED. 455, 458 $(1964)$.
} 
part of those interviewed, it was this: that highly legalistic or idealistic images of what "ought to be"-i.e., of freely given and informed consent-can probably be satisfied through the routinization of consent forms but that the outcome of the medical-research situation itself, as a result of personality factors and subtle pressures that may operate as restrictions on free choice, may often disappoint ideals. Researchers insisted that the decision about which patients to approach for inclusion in a study must be decided on an individual basis in terms of the fitness of a specific patient for a particular study. There was general acceptance of the norm of informed consent, since in its moral dimensions this norm accords with the general principles of the professional ethic of the trained scientist, but there was a strong sentiment among those interviewed that each case is different in terms of the make-up of the patient and of the design of the particular study. There was also evidenced a sentiment for the exceptional case when the rule about informed consent must be suspended. Thus, there appears to be no rejection of the purposes underlying the consent rule, but there is serious doubt as to the viability of formal legal definitions of consent. Thus, experimenters ask the legal proponent to pay close attention to the situation in which "free" consent is expected, and there would seem to be no doubt about the need for lawyers, judges, and administrators to take account of the charge that existing legal doctrine tends to be unrealistic and consequently not adapted to achieving its professed and generally accepted object.

Reviewing some possibilities for restriction on the exercise of free choice by patients and volunteers, one can become sensitized to situational aspects in which free consent giving is expected. Besides those inner compulsions and conflicts which psychology has shown interfere with the ideal of "free choice" in daily life, it is well known that illness drastically reduces the energy and conscious determination of the individual. It is also well known that ill and hospitalized persons show a marked tendency to be dependent. Several studies show that the process of hospitalization itself greatly increases anxiety; ${ }^{42}$ hence if consent is requested during this period inherent restrictions on choice in the patient may be present. Patients who are being treated in an institution where research is also being done are apt to relate requests to do research to their own expectations about treatment. A patient might feel an inner reluctance to disappoint a doctor, even one other than his attending physician, fearing that interest might be lost in "his case." Park's interesting study of the subjective experience of research patients showed that they tended to relate obvious research instruments (questionnaires, one-way mirrors, tape recorders) to their treatment. ${ }^{43}$ Patients tend not to distinguish between research

\footnotetext{
'2 See, e.g., Goldman \& Schwab, Medical Illness and Patients' Attitudes: Somatopsychic Relationships, I4I J. Nerv. \& Ment. Dis. $6_{7} 8$ (1965); Vernon, Shulman \& Foley, Changes in Children's Behavior After Hospitalization, ir I AM. J. Diseases of ChILdRen 58I (1966); Mason et al., Corticosteroid Responses to Hospital Admission, I3 ARch. Gen. PsYch. I (1965).

${ }^{3}$ Park et al., The Subjective Experience of the Research Patient: An Investigation of Psychiatric Outpatients' Reaction to the Research Treatment Situation, I43 J. Nerv. \& Ment. D1s. I99 (I966).
} 
and treatment, and hence entertain an inner sentiment that the procedure, even when they are told it is nonbeneficial, holds out some hope for their improvement. Park's study was conducted with psychiatric outpatients, a majority of whom were in a lower socioeconomic status and who were generally uninformed as to what the psychiatric situation was. Therefore, it is possible that social and educational differences among patients affect in some measure the quality of consent they are able to give.

The psychological situation of "normal" volunteers has been studied in part. Available studies, published and unpublished, show that conflicts of a serious nature appear in a significant percentage of those volunteers examined.4 The types of pressure to which prisoner and student volunteers might be subjected have also been reported elsewhere. ${ }^{45}$ In general, the author agrees with those who would put the sharpest restrictions upon the use of prisoner populations in medical research, since by virtue of their imprisonment they cannot be truly said to possess an active capacity to consent. No argument based on prisoners' availability or on their presumed willingness to recompense for their social deviance relieves others of their responsibility to protect the liberties of all by being realistic as to the temporary loss of liberty of the prisoner. No general rule sanctioning the use of prisoners should be acceptable to the communal conscience; thus, any suggestion that prisoners be used in research must be treated as a rare exception which must be subjected to vigorous public scrutiny. One of the "checks and balances" which should be employed in selection of suitable populations for research is that those who have experienced the most severe form of social control, the loss of public liberty through imprisonment, should not then be made to go through the charade of seeming to possess what has been temporarily removed. ${ }^{40}$

Several physicians noted in interviews that consent from the patient has an "automatic" quality, due to the ready acceptance of the physician by the patient, and this response has also been amply noted in the literature. ${ }^{47}$ Thus the very role perception of the physician by the patient tends to exaggerate his sense of the

\footnotetext{
"National Institutes of Health, Public Health Service, Dep't of Health, Education, and Welfare, How Normal is a Normal Control Patient?, Feb. 13, I958 (unpublished manuscript, Combined Clinical Staff Meeting, Clinical Center); Esecover, Malizz \& Wilkens, Clinical Profiles of Paid Normal Subjects Volunteering for Hallucinogen Drug Studies, Ir7 AM. J. Psych. 9ro (I961); Lasagna \& von Felsinger, The Volunteer Subject in Research, 120 Scr. 359 (1954); Perlin, Pollin \& Butler, The Experimental Sttbject, 80 Arch. Neuroz. \& PsYch. 65 (1958).

${ }^{45}$ See generally Ethics Governing the Service of Prisoners as Subjects in Medical Experiments, 136 J.A.M.A. 447 (1948) (report of a Committee appointed by Governor Dwight H. Green of Illinois); Newman, The Participation of Prisoners in Clinical Research, in I. LAdIMER \& R. NewMan, stupra note I, at 467 .

${ }^{16}$ See generally Remarks of T. Starzl, in ETracs in Medical Progress 75-77; Daube, Transplantation: Acceptability of Procedures and the Required Legal Sanctions, id. at 188, 197, 198 . Daube makes his rule absolute, which in my estimation is too strong, since in ethics to say "never" is to remove onesclf from historical possibility.

${ }^{47}$ See, e.g., Beecher, supra note 40.
} 
doctor's goodness or helpfulness, and out of his own sense of need his power of discrimination is affected.

There are also factors of the same order to consider in those who are asked to consent for others. The attitudes of parents of mentally ill or retarded children are known, in some instances, to be quite ambivalent, a mixture of love, pity, and anger. Such feelings might present themselves in a response to a request for experimentation involving the child. Thus, the psychological situation of the patient's representative may be an effective restriction on "freely given" consent, even though the legalities are observed as carefully as possible with an explanation and signed consent forms. ${ }^{48}$

Related to the patient's education and his sophistication in science is the ability of the investigator to communicate, in lay language, technical aspects of the study to the patient or volunteer. Although reduction to simple terms may suffice to communicate to the patient what is going to happen to him, it is not so simple always to communicate why it is happening. Understanding the purpose of the experiment does assist the patient, in most cases, to give a more informed consent, as Alexander notes. ${ }^{49}$ In actual consent situations with volunteers in which requests were made for explanations of the "purpose" of the study, investigators were observed to experience some difficulty in explanation. Volunteers could be seen to lose their attention in the consent situation when the technical aspects of the study were explained in simple scientific terms. If legal significance is attached to the subject's understanding the technicalities of the experiment, many physicians will express concern.

For a significant number of investigators the Southam-Mandel case assumed large legal proportions. In eight of twenty interviews, the investigator brought up the legal significance of this case voluntarily. Investigators sense their legal insecurity, not only because of the risks inherent in their professional work but also because the laws which do affect the practice of medical researoh are born in malpractice cases. Medical research is perceived to be far out in front of legal and moral consensus as to what is permissible in human experimentation. New definitions and limitations have not been clearly perceived in medicine's new social situation. Part of the striving for new definitions of justifiable behavior and rules to govern new conditions can be interpreted as a desire to harmonize new and innovative acts with the communal conscience. When men take risks with the life and health of members of the community, even when these risks are scientifically sanctioned, and they sense that these risks are questionable in the communal conscience, they can take at least three attitudes: they can become defensive and defend their pursuit of science as a "right"; they can become secretive; or they can share their dilemmas in a dialogue with the public conscience in the attempt to work out

\footnotetext{
${ }^{48}$ Silverman, Informed Consent, 38 Pediatrics 373 (r966).

to Alexander, supra note 2, at 63 .
} 
the actual practice of experimentation in relation to values and commitments held within our pluralist culture.

\section{B. Constituted Rules for Consent: Heteronomy and Autonomy}

The search for legal rules and guidelines for the experimental medical situation, as well as for clarification of moral issues in all aspects of human experimentation, provides a most interesting piece of social history of a segment of modern professional society. It has also become clear to the observer of social ethics that, as in the case of all instances of the protection of the individual against accumulations of power, the issues are never decided once and for all but find continuous outlet in the push and shove of social existence. In the highly organized and specialized climate of science, however, there have been renewed appeals for rules and revisions of rules to provide guidance for new contingencies. ${ }^{50}$ The debate about rules can be seen as swinging between two extremes, between threats of heteronomy (external controls on experimentation) on the one hand and claims of the scientist for autonomy in the research situation on the other.

\section{Rules Governing Use of Minors and Mental Incompetents}

The Nuremberg rules, if interpreted as the only ones applicable to the consent situation, would prohibit research of a general nature in any group of persons who did not possess legal capacity to give consent. Thus, all research done within the mentally ill or with children which is of a nonbeneficial nature and conducted for general information, would be barred. Also prohibited would be research with unconscious or comatose persons, or anyone whose personal environment was so restricted as to fail to meet the demand of capacity. Alexander proposed, in 1947 , six points as a basis for permissible experiments on human beings in a memorandum to the United States Chief of Council for War Crimes and the Court. Alexander noted later that, although all of his points were incorporated and expanded into the final ten criteria, his provisions for obtaining legal and morally valid consent from mentally ill subjects by consultation with the next of kin or from the patient where possible were omitted from Article I. He ventured the opinion that the exceptions were excluded from the final version of the first rule "probably because they did not apply in the specific cases under trial.".51

Would it be justifiable to enforce the Nuremberg rule to the letter? Perhaps the most intensely felt objection to a strict or legalistic interpretation of the consent rule originates from highly motivated researchers who feel a moral imperative to pursue general studies of a nonbeneficial nature in those areas which would be proscribed by the letter of the rule. They consider it morally irresponsible to neglect research in diseases of children or in mental illness. Thus strict application of the Nuremberg

\footnotetext{
${ }^{50}$ See Robin, Rapid Scientific Advances Bring New Ethical Qtestions, 189 J.A.M.A. 624 (1964).

${ }^{51}$ Alexander, supra note 2, at 62.
} 
rule would approach the extreme of heteronomy, for while the rule has great and deserved standing it does not take account of exceptions which can be controlled and makes no allowance whatsoever for the exercise of professional judgment and the investigator's ethical discrimination. The price to be paid would be exacted from gains in knowledge of the sensitive areas mentioned, thus cutting across the general social principle of least suffering.

Following the promulgation of the Nuremberg Code, as we have noted, other statements and regulations incorporated the exception for the representative of the subject, when he is incapacitated or a minor, to substitute in consent giving. An additional example of an institutional formulation assuring protection to incapacitated individuals while making provision for including them in investigative research is the policy of the M. D. Anderson Hospital and Tumor Institute, University of Texas. Following a verbatim statement of the first article of the Nuremberg Code, this qualification appears:

If the subject is not competent, the person responsible shall be the legally appointed guardian or next of kin. If the subject is a minor under $2 x$ years of age, the person responsible shall be the mother or father or legally appointed guardian. ${ }^{52}$

Similar provisions appear in most other codes and guidelines published in recent years. Some of these, however, have included additional safeguards that appear useful and not obstructive of legitimate scientific inquiry. Thus, (I) the AMA permits a minor or mentally incompetent person to be used only if the research could not be conducted with adults or mentally competent individuals as subjects-a principle that should probably always be considered implicit in provisions permitting use of such subjects; (2) the Public Health Service requires obtaining the minor's consent, as well as his parent's or guardian's, if he is mature enough to have some understanding of the procedure and the risks; and (3) several formulations distinguish between therapeutic and nonbeneficial procedures, varying the need for consent accordingly. ${ }^{53}$ These refinements appear to strike an appropriate balance between heteronomy and autonomy, especially as one recognizes the scientist's obligation to apply the formulated standards as meaningfully as possible in particular circumstances.

\section{Resistance to Excessive Scientific Autonomy}

Questions now need to be raised about the second type of exception noted earlier, namely the professional right of the investigator, if he deems it in the subject's interest, to withhold information or to suspend any interaction with the subject in consent giving. Just as there is a danger for the public interest in the rigid insistence on literal obedience to rules requiring informed consent, there is an equal

\footnotetext{
${ }^{62}$ M.D. Anderson Hospital and Tumor Institute, University of Texas Medical Center, Research Investigation Involving Human Beings: Code and Methods of Procedure (1963).

${ }^{53}$ See, e.g., Medical Research Council, supra note 4.
} 
danger in allowing the physician autonomy to determine what the subject shall know. The danger is that physicians will choose-on the basis of their own inhibitions against disclosing a research procedure-to withhold facts which seriously affect the subject's power of discrimination.

Certainly this is the lesson of the Southam-Mandel incident, quite apart from any reflection on the moral quality of these doctors' actions. The researchers withheld a description which, in their estimation, would have caused the patients unnecessary alarm, since in their judgment there was no reason to believe injection of these cells threatened harm. It was the withholding of that information, however, that provoked the Regents' sharpest criticism and occasioned their most specific statement about what constitutes satisfactory consent:

No consent is valid unless it is made by a person with legal and mental capacity to make it, and is based on a disclosure of all material facts. Any fact which might influence the giving or withholding of consent is material. ${ }^{54}$

Thus, the Regents clearly concluded that the wrongdoing in this instance lay in omission of a material fact which could be instrumental in the patient's decision. In other words, it is up to the patient or his representative to decide whether the words "cancer cells" frighten him or not, and not up to the doctors to prejudge the validity of the patient's reaction. There can be little doubt that the reason this central fact about the experiment was suppressed was the investigators' expectation that patients would not volunteer if fully informed.

There were further warnings in the Regents' decision about autonomous decisions by physicians:

There is evidenced in the record in this proceeding an attitude on the part of some physicians that they can go ahead and do anything which they conclude is good for the patient, or which is of benefit experimentally or educationally and is not harmful to the patient, and that the patient's consent is an empty formality. With this we cannot agree. ${ }^{55}$

In other words, there is not adequate public protection in the guiding assumption that the investigator possesses an unqualified power to decide what constitutes adequate and sufficient consent; even though the physician has confidence in the design of his study, abuses of the consent procedure can still occur. On the other side of this observation lies the necessity for the free exercise of the physician's professional judgment and perception as to the subject's personal receptivity to any information that would damage him psychologically or in any other way. Some "mediate" rule would seem to be required, perhaps the sharing of the decision to withhold certain information with a responsible relative, representative, or physician-friend of the subject.

\footnotetext{
54 Board of Regents of the State of New York, reprinted in Langer, stipra note 13, at 664 . ${ }^{55}$ Id.
} 
The newly developed Food and Drug Administration regulation requiring written consent in the use of new investigational drugs appears to incorporate such a "mediate" rule, falling between rigid external control and total dependence on the autonomy of the investigator. ${ }^{56}$ The regulation presupposes that consent will be obtained in every case, and the only possible exception is based on the patient's own well-being, after the physician has concluded, on the basis of professional judgment, that the exception is relevant. No argument precluding consent which is based on the convenience of the physician is acceptable.

The FDA regulation recognizes many of the limitations to freely given consent which have been discussed. For example, there may be occasions when it is not feasible to receive consent; for example, where it is impossible to communicate with the patient or his representative, such as when the patient is in a coma and the drug must be quickly administered. In requiring written consent at that stage of drug experiments when it is initiated in treatment, the regulation makes an additional exception to the basic written consent requirement that is based solely on the health and welfare of the patient, but it still requires oral consent and a statement of the fact of consent in medical records. This regulation appears to be an attempt to resolve the possible conflict of interest in the case of experimental drugs by coming out fundamentally on the side of the patient's interests.

\section{Experimental Necessity as a Basis for Dispensing With Consent}

A particularly troublesome objection to the consent requirement in experimental situations is the attitude that, if full disclosure of the experimental design and variables which are operative is made to the subject, the observed results will be less reliable because of the psychological variables induced. The use of placebos is intended to determine to what extent the subject's psychological state is responsible for the observed change. The principle behind the placebo may be extended to keeping the investigator or physician who is in contact with the subject from knowledge of the identity of the variable in question.

Not all experienced investigators agree that disclosure of the use of a placebo will actually inhibit valuable results. Alexander, writing specifically out of consent situations with psychiatric patients, gives evidence that disclosure of use of a placebo can be made to patients without interference with the unbiased attitude necessary for establishing the results of the test. ${ }^{57}$ The findings of Park and Covi correlate with Alexander's experience. In a study before which patients were told frankly that a placebo was to be used and the word defined for them, they later

\footnotetext{
${ }^{50}$ See note Io stpra. In interviews with officials of the Food and Drug Administration, the author asked how the new regulation was working out in the field. In general the response was that it was too early to tell. The "mediate" approach which is noted in the paper is corroborated by the fact that the FDA does not require evidence as to written consent, but the sponsor of the experiment must certify that the expectation is being met.

${ }^{87}$ Alexander, stipra note 2, at 63 .
} 
reported that the patients accepted treatment and responded with a wealth of fascinating subjective material. ${ }^{58}$ These remarks would indicate that preconceived opinions about disclosure need to be more widely tested. Park and his associates comment on some of the underlying causes of overly scrupulous secrecy in research:

[T] he importance of being honest and straightforward with patients should be considered in setting up research procedures. We tend to become inappropriately secretive because of our own apprehensions that the patient might discern the experimental nature of procedures and/or might be able to infer that our primary purpose may be research findings rather than immediate alleviation of distress. ${ }^{\text {t9 }}$

The conflict with a legal or moral consent requirement is most marked when the fact of experimentation itself is withheld from the subject on the ground of experimental necessity. It may be the sincere judgment of the investigator that the subject's psychological response to the fact of experimentation may invalidate the obtained result, even when the subject has consented to participate. On the other hand, knowledge of the experiment may itself be the variable being manipulated. In either case, if participation involves any risk, the legal and moral problems are immense.

The conflict between the consent requirement and experimental necessity cannot, of course, be resolved here. Research is needed on the validity of research conducted under conditions of full disclosure and on other means of eliminating, detecting, and accounting for, or otherwise minimizing psychological factors in experimental situations. There is a strong and understandable tendency on the part of investigators to wish all psychological factors out of any experimental situations in order that results might be more reliably quantified. Unfortunately, the desire to eliminate such variables may reflect, in some cases and in some immeasurable part, an exaggerated mistrust by the physician of the validity of patients' judgment and understanding, a mistrust that may also cause the physician to undervalue the importance of the patient's informed consent. Because of this possibility, that conviction about the experimental necessity of dispensing with consent may accompany an undervaluation of consent's ethical importance, special care is called for.

Perhaps nowhere are the ethical issues apt to be drawn so clearly as where experimental necessity is advanced to warrant a dispensation from the consent requirement. Certainly approval of an interdisciplinary peer-group should be a prerequisite to the granting of exceptions in this area, and the burden on the investigator should be a heavy one. Moreover, scientific ingenuity should be insisted upon to avoid easy escape from disclosure requirements; for example, increased use of psychological tests might be recommended, or emphasis might be placed on twostage experimental designs which first use informed subjects and only later use blind

\footnotetext{
${ }^{68}$ Park \& Covi, Non-blind Placebo Trial, I2 ARch. Gen. Psych. 336, 344 (1965).

${ }^{59}$ Id.
} 
or double-blind techniques to verify the initial results when the risk factor has been shown to be minimal. The burden on the medical profession is to reconcile the scientific mission with the rights of its experimental subjects. Some autonomy must be accorded here, but the community conscience must likewise be accorded a role in decision making.

\section{Conclusions on the Roles of Rules and Professional Responsibility}

Who will set and enforce the rules as to the adequacy of consent? Posing the question in this fashion constellates the tension between heteronomy and autonomy, and every move is interpreted as constraint. Neither type of rule will serve medical research at this juncture. Constituted rules born out of constitutive principles of cooperation between skilled investigators and informed subjects have more promise. The polarity between those who feel that there should be no interference at all in research procedure and the possibility revealed in the Regents' decision for external regulation of consent practices can be broken down by more cooperative approaches to consent problems.

There is a genuine public interest to be protected in the practice of human experimentation; namely, candidates for experiments do not, with few exceptions, come to the experimental situation seeking employment. They are brought there by virtue of their being ill or in a specific situation which presents a researcher with a problem to study. Physical, social, and psychological conditions, each a part of personal and social existence, present themselves to the research group through the subject. Usually the investigator himself is the party who seeks out the candidate. Insofar as he has no a priori right-after the fashion of the government to draft men for military service - to recruit candidates for research, the public interest is protected when assurance is given that the methods for the conduct of the research accord with the voluntary nature of its recruitment and that what transpires in the consent situation provides the subject with adequate information and sufficient freedom, in that particular situation, to have a meaningful choice.

The fact that some subjects in research are remunerated for participation in a study should in no way relieve the investigator of responsibility to obtain informed consent just as he would in the event of nonpaid participation. If some volunteers for experiments are motivated primarily by financial considerations, then special care must be exercised by the investigator to distinguish between the role of money in the research contract and the role of informed consent. Money compensates the subject for the use of his time and the cost of his cooperation, and it in no way replaces informed consent as the main facet of the research contract. It is possible that the subject's expectation of financial gain could even be a restriction on his judgment and choice, and thus the economic status of research subjects becomes a relevant factor in the dynamics of the consent situation. As Lord Henley noted 
in 1762 , "Necessitous men are not, truly speaking, free men, but, to answer a present exigency, will submit to any terms that the crafty may impose upon them." ${ }^{\text {"10 }}$

On the other hand, the clinical investigator has good reason to resist rigid codes which attempt to give specific, coded instructions on how to meet the requirements of the consent situation. The consent situation is an interpersonal encounter involving many variables. No set of rules can cover all the possibilities. One of the differences between traditional and open societies is that, in the former, groups of people are governed by specific sets of regulations which are highly ordered, rigid, and numerous, while in the latter, characterized by high mobility and social movement, moral rules are considerably less clear, though more flexible and considerably variable in number. ${ }^{61}$ Physicians tend toward a more "situational" moral approach (as do many other professionals), which allows specific data in each new situation to be weighed in a decision, and they generally insist on being free from any one intrinsically defined principle of right or wrong action. ${ }^{62}$

It is far easier simply to act on the basis of an abstract principle than it is to make a fitting response to new situations on the basis of concrete and immediate responsibility. But the former course does not lead to the quality of responsibility which is necessary in today's medical setting. The individual uniqueness of each patient is not served by the kind of codification which would require stereotyped actions in each situation. The existing ethical codes of medical research are sufficient to inform the public of the medical profession's recognition of the principles which underlie informed consent; what remains to be accomplished, in the author's opinion, is an adequate demonstration to the public that the problems of consent giving and its dilemmas are being explored in as attentive a fashion as other obligations of the social responsibility of science. Significantly new methods of cooperation between experimental science and the public must be attained in order for science to keep the confidence of the public, which bears the major costs for medical research. Along these lines, cooperative methods of communication need to be developed to keep the public informed and assured that subjects in research (or their representatives), especially those in whom nonbeneficial procedures are carried out, (a) know that they are in an experimental procedure; $(b)$ have been informed as to all essential aspects; $(c)$ have assistance in making a decision to perceive the factors relevant to consent giving; and $(d)$ are free to withdraw from the experiment at any time. The wide public discussion of consent is one indication that these popular expectations are being heeded. Much more careful study of actual consent situations in research is necessary, however, to ascertain responsibly how effectively those broad expecta-

\footnotetext{
${ }^{60}$ Vernon v. Bethell, 28 Eng. Rep. 838, 839 (Ch. 1762).

${ }^{61}$ H.D. AlKEN, supra note 38 , at 72 .

65 See Beecher, Some Guiding Principles for Clinical Investigation, 195 J.A.M.A. 1135 (1966); Merrill, Clinical Experience is Tempered by Genuine Human Concern, I89 J.A.M.A. 626, 627 (1964); Josepu FintCher, supra note 38, at 26 .
} 
tions are being met. Some concrete proposals for research will be made at the end of the article.

\section{Ethical Principles}

Adequate ethical reflection is rooted in the real, arises out of situations of actual conflict, and involves itself with the justifications which persons in society make of their specific decisions. The level of principles is reached on this level of moral language when the parties to a dispute or a decision reflect on the question: am I really justified in acting according to the mandate, imperative, or rule which I perceive as governing my decision? ${ }^{63}$ Thus, the level of principle is reached in a deeper and more reflective moment in decision making than is ordinarily realized in the press and heat of a conflict. Ordinarily, what can be observed as a moral conflict involves justifications of actions taken or anticipated which the actors in the situation perceive as necessary.

"Principles" can be functionally interpreted as socio-psychic categories found at a deeper level of justification, upon which we fall back to uphold our ways of handling situations in which values and norms are perceived to be in conflict. Principles clearly have theological possibilities because they will ever involve, at their deepest symbolic level, some image of the way the actor interprets himself and his world. For example, in the report of a case of heterotransplantation of the heart, the authors justify the substituted transplantation of a primate heart into a man when the human donor planned to be used had not expired, on the grounds that "although survival was not achieved, the situation was one in which the patient had no chance, except for the slim possibility that the transplant could be made to support the circulatory requirements and rejection could be prevented."64 If the authors had gone on to spell out what the implications to them of what "having no chance" meant, how the principle of life or vitality lent deeper sense or meaning to the action which is being justified, they would have been involved in justification at the level of principle.

Other authors from the religious, philosophical, and legal communities have attempted to identify principles at this level which would finally justify both the practice of medical experimentation and the legal safeguarding of those who surrender some of their autonomy and freedom to facilitate a socially desirable enterprise. $^{05}$ While remaining aware of the temptations of self-deception, on the theological level, in seeking any ultimate justification by principles, we must nevertheless employ them to bring some proximate order into the press and conflict of decision making in society. The author's basic orientation is to Christian com-

\footnotetext{
${ }^{63}$ H.D. AlkeN, supra note 38 , at 75 .

os Hardy et al., Heart Transplantation in Man, I88 J.A.M.A. II32, II39 (1964).

${ }^{\circ 6}$ See generally Leake, Technical Triumph and Moral Muddle, in T. StARzI, Experience IN RENaL Transplantation 363 (1964); Stumpf, supra note 2; Freund, supra note 2; Giuseppe, Human Experimentation-A World Problem from the Standpoint of Spiritual Leaders, 7 WordD MED. J. 80 (I960); Pius XII, The Moral Limits of Medical Research and Treatment, 44 ACTA Apostolican Sedis 779 (I952).
} 
munities as agencies of the growth and renewal of communities of persons in modern culture. He has learned much from colleagues who, though not sharing an explicitly theological perspective, show deep reverence for the mystery of human existence and an active concern for those who are imperiled by catastrophic social changes. There is much to be said, in this day of gigantic organizations, for laboring for social arrangements which will enhance the autonomy of the person and his need to control his own physical and social environment. Concern for civil rights in the spheres of public action is compatible with concern for the maximum conscious participation of those involved in experiments, within the limits of the situation. Defining a principle helps to locate the argument in a social and historical sense and to identify oneself and provides an operational norm for judgment which must always be subject to change. Thus the author seeks to argue that the principle of mutuality between persons, or "perceived effective decision making" is the relevant ethical principle for the consent situation. This principle is seen as especially relevant to requests for participation in nonbeneficial studies.

To illustrate: Two group consent situations were observed by the author. Each included a meeting between a senior investigator, his associates, and a small group of normal volunteers. Each meeting was similar in its structure: (a) a careful and technically documented explanation of the study, its purpose, duration, risks, and discomforts; $(b)$ a period for questions; and $(c)$ the giving of instructions as to decision making and the signing of consent forms. The meetings varied in content only in the third point. The first senior investigator, after stressing that none of the group had to furnish a reason for deciding against participation, asked the members to go to their rooms if they cared to, study the consent form, which contained the appropriate information, and turn them in signed or unsigned when a decision had been reached. At the similar point in the other meeting, the senior investigator passed out consent forms, asked the members to read them there, sign them there, and after reminding them of their freedom to withdraw, suggested that if any member planned not to enter the study, he wanted them to "back out now instead of later," after the study had begun.

This observer concluded that there was more latitude, if a group member required it, for the exercise of personal choice in the way the first situation was handled than in the second. Time was afforded each individual to absorb the technicalities, study the form, and make a decision apart from the group. There was careful definition of the meaning of withdrawal insofar as the necessity for furnishing reasons was involved. In the second situation there was more opportunity for group pressure to work, no time was allowed for "second thoughts," and the request for withdrawal was made so that response was suggested immediately. If a member had entertained thoughts of withdrawal, it could possibly have been more difficult to have brought them out in the group than later. In both cases the majority of the mem- 
bers belonged to a religious service organization in which individual differences between members tended to be submerged in a common "service" aim. Perception that it would be more difficult, in this particular group, for individuals to express doubts or questions in front of fellow members would call for preference of the first means of instructing. How the consent-seeker perceives the opportunities for volunteers or patients to exercise what control they do possess over decision making and how he helps to open these opportunities can enhance the degree of selfpossession and hence the degree of mutual cooperation.

In attaching significance to the principle of personal autonomy the author is cognizant of the degree to which the power of decision of the very ill person in an experimental setting is greatly diminished. An investigator cannot create a strong ego for a patient or subject, but there are leads he can follow to stimulate what he does find in the person. A sensitive investigator can enhance the consent situation for the normal subject or patient by assisting him to perceive what it is that he does have control over; that is, his consent. Some physicians when interviewed revealed confusion about the content of patients' consent. Some indicated that they thought informed consent meant that the patient is expected to agree intelligently to the design of the experiment or to the details of a new therapy, and thus they could easily despair of ever attaining consent or were wary of seeming to relinquish professional medical judgment. The expectation of informed consent was never that the patient be a judge of the medical procedure in the consent situation. What is hoped for is the most self-possessed decision to give consent, to say "yes" or "no" to participation. The roots of the word consent (con-sentio) point not only to mutual understanding between the parties but to an answer which proceeds from within the person, involving feeling and perception. The most serious moral question which can be addressed to those who participate in the consent situation is this: How can the subject be helped to employ what power of decision he does possess? Can the interaction be turned to the mutuality of the persons involved so that fears of manipulation and deception can be transmuted into meaningful cooperation between equals in the research procedure? Such questions are derived from the principle of persons-in-mutuality, so integrally related in its development to the personalizing meaning of agape, the central focus of Christian ethics.

The two values which could come into conflict in the consent situation, the general welfare and the welfare of the individual, must be balanced and harmonized in the consent situation itself. It is not accidental that nonscientists have become concerned and involved in the debate about consent. Some have taken care to develop the category of "private personality" in the research sphere. ${ }^{66}$ The author's own convictions find accord here. One could also generalize from Bettelheim's studies of the loss of autonomy in modern man, as well as from his revealing work on the development of autism in children, to the lack of subject participation in the consent

\footnotetext{
${ }^{80}$ Ruebhausen \& Brim, supra note 2, at 423 .
} 
situation. ${ }^{67}$ Do patients and subjects in the research situation perceive that their decisions to consent actually "make a difference" or affect the environment in any real way? Is this situation similar to so many others in society in which the less the individual is able to solve the strains between what his environment demands and what he himself wants, the more he relies on those who appear in the environment to furnish the cues for his behavior? There has been much written on the "responsible investigator" in medical research as the most effective protection and safeguard to the patient. ${ }^{68}$ This is not in dispute, but could not some potential be found in the concept of the "responsible subject"? Moves which have been made to study the subjective attitudes of research subjects are most welcome. What needs to follow is a responsible investigation of the consent situation in its many settings and forms. The first form for study should probably be the one to which investigators assign the most difficulty, consent for nonbeneficial procedures in ill persons.

IV

\section{HYPOTHESES FOR RESEARCH}

Means to deepen the legal, scientific, and personal effectiveness of the interactions of consent in medical research should be of interest to all who take responsibility for the conduct of investigative procedures in man. There has been extensive writing in the field of human experimentation in the realm of principles and constraints, namely, in the realm of "what ought to be." There have been no investigations, to the author's knowledge, of the dynamics and interactions of the consent situation in experimental research. Since consent situations occur as a requirement of engaging each new participant in nontherapeutic general studies, and since the consent situation is the subject of many opinions in the fields of ethics, law, and science, it would seem reasonable to investigate the consent situation more thoroughly and deliberately.

Suggestions have arisen in several quarters that two physicians in the consent situation would improve the quality of consent obtained. ${ }^{60}$ One of them would be the principal investigator, of whom the rule requires that he be the seeker of consent and the judge of its quality; he may not delegate this responsibility to another. Also in the situation would be another physician, either the patient's attending physician or one known to the patient. In the case of the volunteer, he could be an informed physician who had no vested interest in the experiment. The hypothesis for study would be this: there are fewer second thoughts and fears about participating in an experiment of the nonbeneficial type when the attending physician, or some other informed person known to the patient, is present in the consent situation when the principal investigator is obtaining consent.

\footnotetext{
${ }^{67}$ B. Bettelaheim, The Informed Heskt 72 (1960); B. Bettelhejm, The Empty Fortress 45 (1967).

${ }^{88}$ Beecher, stspra note 62.

${ }^{69}$ Guttentag, supra note 36 ; Beecher, supra note 62 .
} 
A second area of study would center on the restrictions of choice which operate on patients and volunteers in research situations. These forces and inhibitions need to be specified so that, by generalizing from findings, the sensitive investigator can respond more fittingly. Since we know that patients will generally accede to any reasonable request in a medical setting and that some physicians have noted that consent giving has an "automatic" quality about it, another hypothesis for research is this: patients whose consent is requested for nonbeneficial procedures perceive that their decision is more "under their control" and "makes a difference" when there are two visits for consent, one in which the investigator makes an explanation of the purpose, duration, and risks of the study and another when he returns to receive the patient's decision. Implementing these and similar studies would not resolve the basic moral dilemmas, but much could be learned about the decisions which men are asked to make and about the impediments which keep them from making a fitting personal choice. By looking more deeply within its own situation, medical research can perhaps be an agent of more human management of a problem area which has become a source of major public and legal concern. 